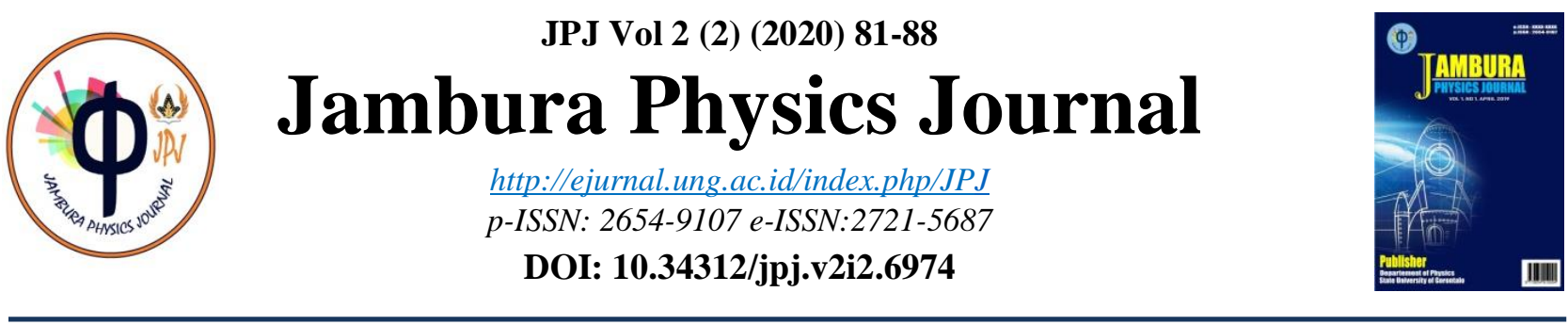

\section{IDENTIFIKASI KEDALAMAN INTRUSI AIR LAUT DI DESA BASSIANG KECAMATAN PONRANG SELATAN KABUPATEN LUWU MENGGUNAKAN METODE GEOLISTRIK}

\author{
Fitri Jusmi $^{1 *}$, Kurnia Bakri ${ }^{1}$ \\ ${ }^{1}$ Universitas Cokroaminoto Palopo, Jln Latamacelling No. 9 B, Palopo 91911, \\ Indonesia
}

Accepted: Juli 04 2020. Approved: September 142020 . Published: Oktober 012020

\begin{abstract}
ABSTRAK
Penelitian ini bertujuan untuk mengidentifikasi kedalaman intrusi air laut ke akuifer berdasarkan nilai resistivitas hasil deteksi menggunakan metode geolistrik konfigurasi schlumberger di Desa Bassiang Kecamatan Ponrang Selatan Kabupaten Luwu. Metode yang digunakan dalam penelitian ini adalah survey lapangan dengan pengambilan data dilakukan pada 3 titik lintasan menggunakan metode geolistrik konfigurasi schlumberger. Akuisisi data lapangan dianalisis dengan menggunakan perangkat lunak microsoft excel untuk memperolah nilai resisitivitas semu dan kemudian diolah menggunakan software IP2WIN untuk memperoleh nilai tahanan jenis yang sebenarnya. Hasil nilai resistivitas sebenarnya yang telah diperoleh dari 3 titik lintasan pengukuran kemudian dikorelasikan untuk menampilkan gambaran penampang tahanan jenis 2D daerah penelitian yang digunakan untuk mempermudah interpretasi data. Hasil penelitian menunjukkan bahwa intrusi air laut ke akuifer air tanah terjadi pada lintasan 1 mulai dari kedalaman 10,8418,92 meter dan lintasan 3 yang semua lapisannya telah terserap oleh air laut. Kemudian untuk lintasan 2 sendiri intrusi air laut ke akuifer air tanah tidak ditemukan sehingga daerah pada lintasan 2 adalah yang paling baik digunakan oleh masyarakat dalam pembuatan sumur sebagai solusi dari masalah air bersih.
\end{abstract}

Kata kunci: intrusi; akuifer; resistivitas; schlumberger

\section{PENDAHULUAN}

Permasalahan kualitas air bersih telah sering terjadi pada daerah yang terletak di pesisir pantai atau daerah yang tidak jauh dari laut, salah satunya di Desa Bassiang Kecamatan Ponrang Selatan Kabupaten Luwu yang juga merupakan daerah pesisir pantai.

Pada daerah ini terdapat sumur gali dan sumur bor yang merupakan milik warga.

\footnotetext{
${ }^{*}$ Alamat korespondensi

Email: fitrijusmi@gmail.com
} 
Namun, warga seringkali mengeluhkan rasa asin pada air sumur tersebut. Berdasarkan informasi tersebut dimungkinkan rasa asin pada air sumur tersebut diakibatkan oleh adanya intrusi air laut ke lapisan akuifer air tanah. Untuk mengatasi masalah ini, maka perlu untuk mengetahui kedalaman akuifer air tanah yang tidak mengalami intrusi air laut sebagai acuan bagi warga pada daerah tersebut untuk membuat sumur gali ataupun sumur bor.

Untuk mengetahui keberadaan air tanah maupun adanya intrusi air laut di bawah permukaan tanah dapat dilakukan dengan menggunakan metode resistivity (Ambarsari, 2013). Metode resistivity juga disebut metode geolistrik. Metode geolistrik merupakan metode yang menggunakan prinsip aliran arus listrik dalam menyelidiki struktur bawah permukaan bumi. Aliran arus listrik mengalir di dalam tanah melalui batuan-batuan dan sangat dipengaruhi oleh adanya air tanah dan garam yang terkandung di dalamnya. Oleh karena itu, metode geolistrik dapat digunakan pada penentuan akuifer maupun kontaminasi air tanah.

\section{KAJIAN PUSTAKA}

\section{Akuifer}

Formasi-formasi yang berisi/menyimpan air tanah disebut sebagai akuifer. Jumlah air tanah yang dapat diperoleh di setiap daerah tergantung pada sifat-sifat akuifer yang ada di bawahnya. Akuifer atau lapisan pembawa air atau lapisan permeabel adalah batuan yang mempunyai susunan yang dapat mengalirkan air (Indarto, 2012).

\section{Air Tanah}

Air tanah merupakan bagian air di alam yang terdapat dibawah permukaan tanah. Pembentukan air tanah mengikuti siklus peredaran air di bumi yang disebut daur hidrologi, yaitu proses alamiah yang berlangsung pada air di alam yang mengalami perpindahan tempat secara berurutan dan terus menerus (Kodatie, 2012)

Proses terbentunya air tanah sendiri diawali dari air laut karena panas matahari berubah menjadi uap, lalu oleh angin uap tersebut ditiup ke atas daratan, pada tempat yang berelevasi tinggi uap tersebut akan mengalami pemampatan, dan setelah titik jenuhnya terlampaui akan jatuh kembali ke bumi sebagai hujan. Air hujan sebagaian besar akan mengalir ke permukaan seperti sungai, danau, dan rawa. Sebagian kecil akan meresap ke dalam tanah, yang bila meresap terus hingga dekat permukaan akan diuapkan kembali lewat tanaman (Cristine \& Sutandi, 2012).

Lapisan batuan ada yang lolos air atau biasa disebut permeable dan adapula yang tidak lolos atau kedap air yang biasa disebut impermeable. Lapisan lolos air misalnya tediri 
dari kerikil, pasir, batu apung, dan batuan yang retak-retak. Sedangkan, lapisan kedap air antara lain terdiri dari napal dan tanah liat atau lempung. Sebetulnya tanah lempung dapat menyerap air, namun setelah jenuh air tanah jenis ini tidak dapat lagi menyerap air (Cristine \& Sutandi, 2012).

\section{Intrusi air laut}

Intrusi air laut adalah proses masuk atau menyusupnya air asin menggantikan air tawar didaerah pesisir pantai. Dalam keadaan statis, air tawar akan mengapung di atas air asin di daerah pantai karena air asin mempunyai densitas yang lebih tinggi dari air tawar (Astutik dkk, 2016). Salam (2011) menyatakan bahwa kedalaman batas (interface) air tawar dan air asin adalah sekitar 40 kali ketinggian muka air tanah dari muka air laut. Kedalaman bidang temu ini tergantung pada kedudukan paras air tanah tawar yang dihitung dari muka laut.

\section{METODOLOGI PENELITIAN}

\section{Metode Geolistrik}

Teori dasar yang digunakan pada metode geolistrik resistivitas ini adalah hukum ohm yang menyatakan, arus yang mengalir (I) pada suatu medium adalah sebanding dengan tegangan $(\mathrm{V})$ yang terukur dan berbanding terbalik dengan resistansi $(\mathrm{R})$ medium dan dapat dirumuskan:

$$
\begin{aligned}
V & =I . R \\
R & =\frac{1}{\sigma} \frac{l}{A}=\rho \frac{l}{A} \\
\rho & =\frac{R A}{l}
\end{aligned}
$$

\section{Konfigurasi Schlumberger}

Konfigurasi Schlumberger menggunakan empat buah elektroda dengan dua buah elektroda potensial dan dua buah elektroda arus yang disusun dalam satu garis lurus

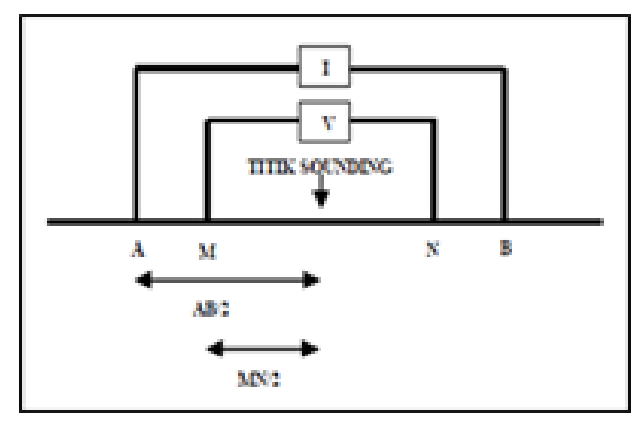

Gambar 1 Aturan konfigurasi schlumberger (Sumber: Wijaya, 2009) 
dengan susunan jarak elektroda potensial lebih kecil daripada jarak elektroda arus.

Gambar 1 memperlihatkan bahwa elektroda $\mathrm{M}$ dan $\mathrm{N}$ digunakan sebagai elektroda potensial dan elektroda A dan B digunakan sebagai elektroda arus dengan jarak pada masing-masing elektroda, $r l=(L-l), r 2=(L+l), r 3=(L+l), r 4=(L-l)$ dengan $L=A B / 2$ dan $l$ $=M N / 2$.

Jarak masing-masing elektroda di atas di subsitusikan ke Persamaan (3) sehingga diperoleh harga $K$ untuk konfigurasi Schlumberger adalah:

$$
K=\pi \frac{\left(L^{2}-l^{2}\right)}{2 l}
$$

Berdasarkan harga $\mathrm{K}$ yang diperoleh maka harga tahanan jenis semu (apparent resistivity) untuk konfigurasi Schlumberger dapat dihitung dengan persamaan:

$$
\rho_{a}=k \frac{V}{I}
$$

\section{Analisis Data}

Data yang diperoleh dari hasil pengukuran di lapangan kemudian diinput ke dalam microsoft excel untuk menghitung harga resistivitas semu $\left(\rho_{\alpha}\right)$ menggunakan persamaan 5 . Kemudian diolah menggunakan software IP2WIN untuk memperoleh nilai resistivitas material bawah permukaan, ketebalan dan kedalamannya yang ditampilkan dalam bentuk grafik dan tabel yang apabila dikorelasi akan menampilkan penampang resistivitas lapisan bawah permukaan $2 \mathrm{D}$.

\section{HASIL DAN PEMBAHASAN}

Pengukuran dilakukan dengan 3 lintasan, dimana untuk lintasan 1 berada pada titik koordinat $3^{\circ} 12^{\prime} 20.06^{\prime \prime S}-120^{\circ} 22^{\prime} 12.37^{\prime \prime E}$ dan $3^{\circ} 12^{\prime} 16.97^{\prime \prime S}-120^{\circ} 22^{\prime} 11.40^{\prime \prime E}$, untuk lintasan 2 berada pada titik koordinat $3^{\circ} 13^{\prime} 15.78 " S-120^{\circ} 22^{\prime} 11.62^{\prime \prime E}$ dan $3^{\circ} 13^{\prime} 12.82^{\prime \prime S}$ $120^{\circ} 22^{\prime} 13.60^{\prime \prime} \mathrm{E}$ dan untuk lintasan 3 berada pada titik koordinat $3^{\circ} 13^{\prime} 33.0^{\prime \prime S}$, $120^{\circ} 22^{\prime} 18.14^{\prime \prime E}$ dan $3^{\circ} 13{ }^{\prime} 31.24^{\prime \prime S}, 120^{\circ} 22^{\prime} 16.43^{\prime \prime E}$. Ketiga lintasan berada pada ketinggian 10 mdpl dengan panjang lintasan 100 meter dengan titik lintasan sebanyak 13 titik pengukuran.

Hasil model inversi penampang bawah permukaan untuk lintasan 1 diperoleh grafik seperti pada gambar 2(a) dengan nilai resistivitas sebesar $0,22-107,7 \Omega \mathrm{m}$ dan nilai error sebesar 0,284\%, untuk lintasan 2 diperoleh grafik seperti pada gambar 2 (b) dan nilai resistivitas sebesar 3,849-1999 $\Omega \mathrm{m}$ serta nilai error sebesar 0,243\%, sedangkan untuk 


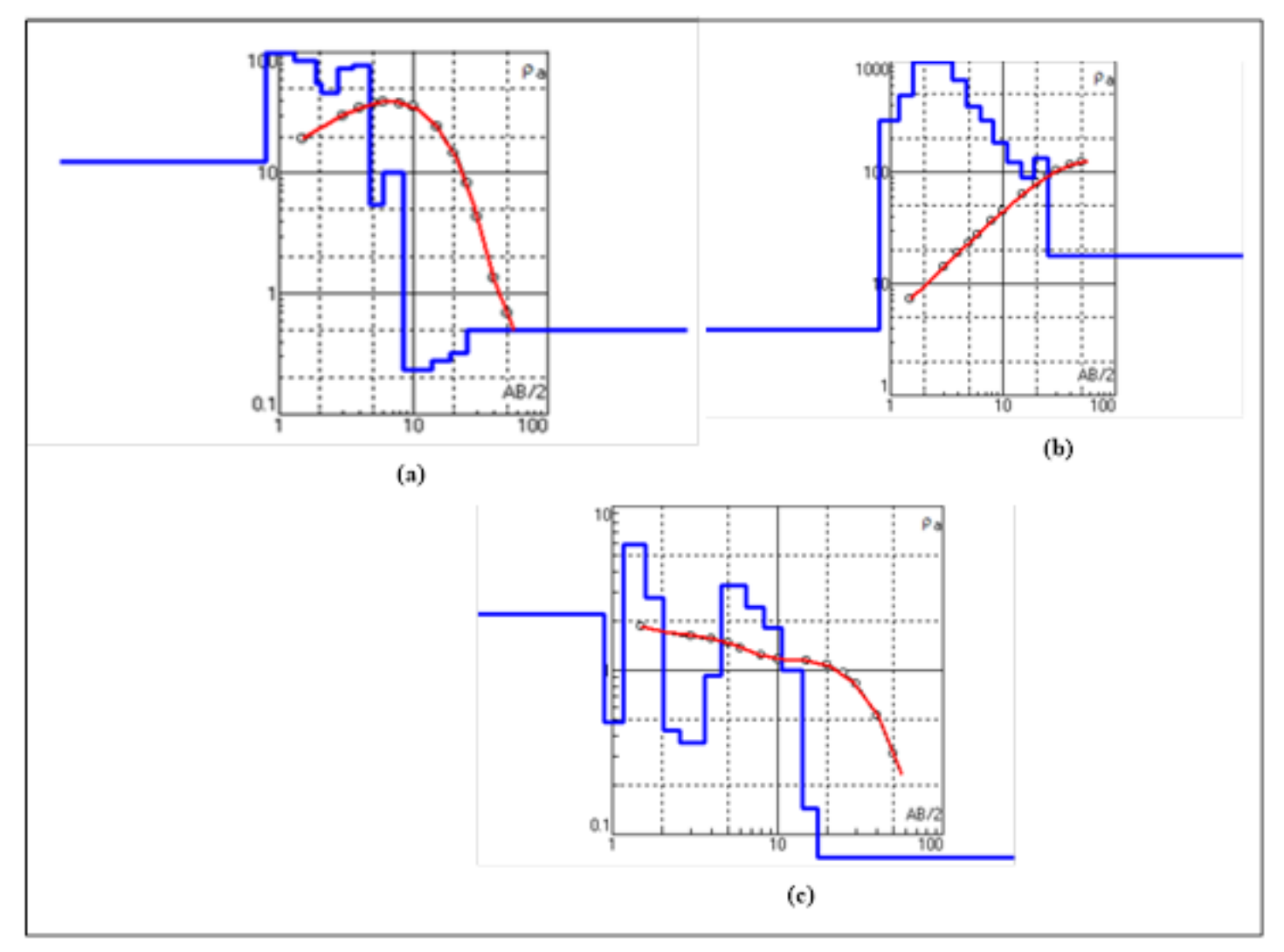

Gambar 2 Grafik hasil pengolahan data VES pada (a) lintasan 1, (b) lintasan 2 dan (c) lintasan 3

lintasan 3 diperoleh grafik seperti pada gambar 2 (c) dan nilai resistivitas sebesar 0,01 $\Omega \mathrm{m}-3,27 \Omega \mathrm{m}$ serta nilai error sebesar 0,296\%.

Pengindikasian batuan bawah permukaan berdasarkan nilai tahanan jenisnya didasarkan atas kondisi geologi daerah penelitian merupakan formasi alluvium. Kondisi tanah pada lintasan 1 dan 2 merupakan tanah yang ditumbuhi pohon dan semak-semak sedangkan kondisi tanah pada lintasan 3 merupakan tanah berpasir. Menurut Astutik dkk, (2016) yang melakukan penelitian tentang Identifikasi Intrusi Air Laut Menggunakan Metode Geolistrik di Desa Kampung Baru, Tanah Bumbu menyatakan bahwa intrusi air laut mudah menyusup ke dalam lapisan bawah permukaan pada kondisi tanah berpasir dan tidak bisa meresap jauh ke bawah permukaan pada kondisi tanah yang ditumbuhi oleh pohon dan semak-semak. Sehingga dimungkinkan bahwa kondisi tanah pada lintasan 1 dan 2 intrusi air laut tidak mudah menyusup ke dalam lapisan bawah permukaan berbeda dengan lintasan 3 yang mudah terintrusi air laut.

Pada lintasan 1 dengan nilai resistivitas mulai dari 0,50-107,7 $\Omega \mathrm{m}$ untuk citra warna hijau pada penampang dengan rentang nilai resisitivitas 5,5-12,16 $\Omega \mathrm{m}$ diindikasikan sebagai lapisan lempung. Citra warna kuning-orange dengan rentang nilai resistivitas 46$84 \Omega \mathrm{m}$ diindikasikan sebagai lapisan lanau dan lanau pasiran. Citra warna merah muda 


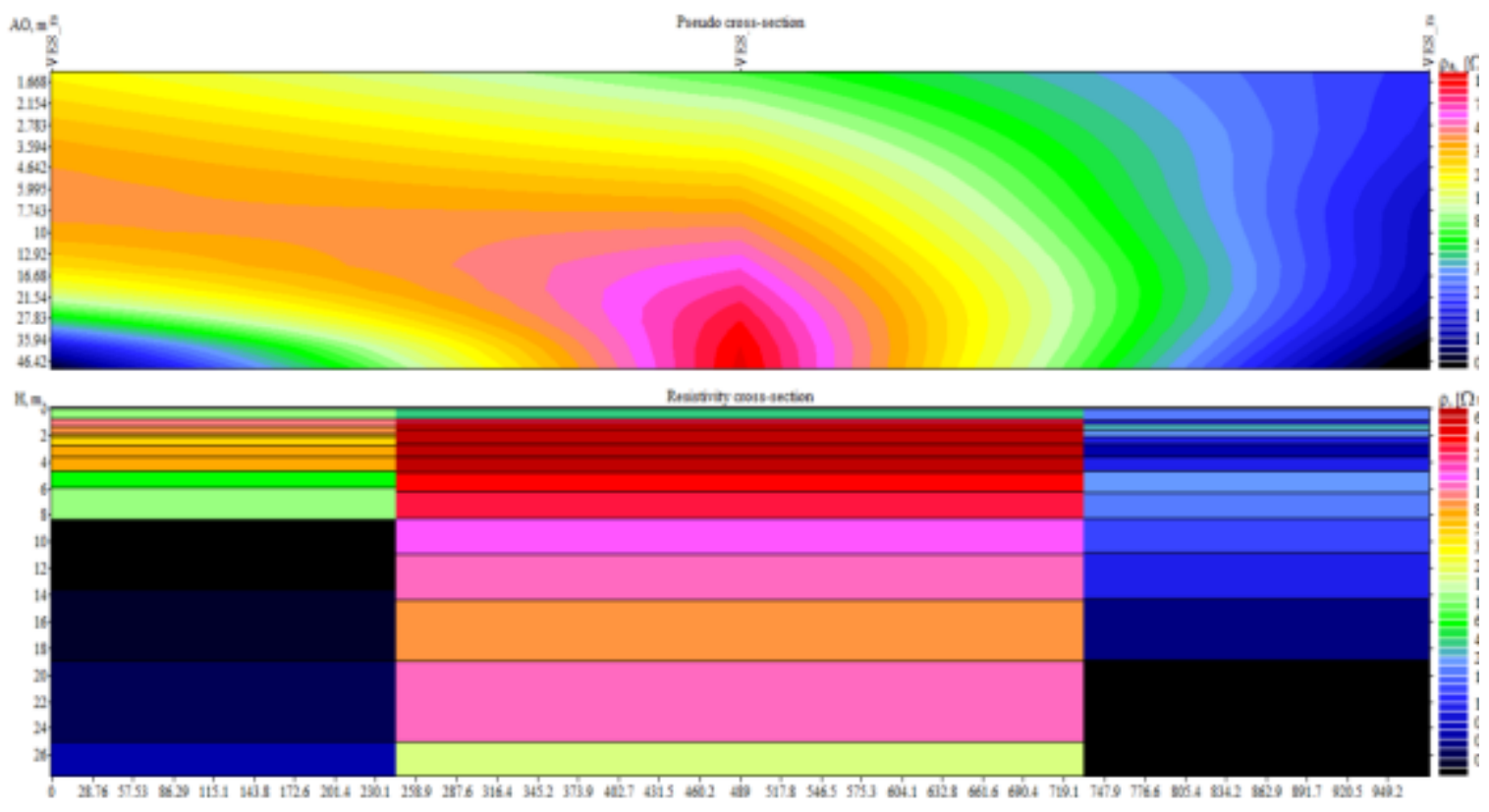

Gambar 3 Citra penampang VES 2D korelasi lintasan 1, 2 dan 3

dengan nilai resistivitas $107,7 \Omega \mathrm{m}$ diindikasikan sebagai pasir-kerikilan. Kemudian untuk rentang nilai resisitivitas antara $0,22-0,50 \Omega$ m diindikasikan sebagai zona akuifer air tawar yang telah mengalami intrusi air laut, nilai tersebut berada pada lapisan ke 10-13.

Pengindikasian lapisan ke 10-13 sebagai zona intrusi air laut disebabkan karena nilai nilai resistivitas air tanah adalah $0,5 \Omega \mathrm{m}$ dan resistivitas air laut adalah $0,2 \Omega \mathrm{m}$ sedangkan berdasarkan penjelasan pada kajian teori mengenai intrusi air laut menyatakan bahwa dalam keadaan statis, air tawar akan mengapung di atas air asin di daerah pantai karena air asin mempunyai densitas yang lebih tinggi dari air tawar. Sehingga, karena pada lintasan 1 lapisan yang memiliki nilai resistivitas $0,22 \Omega \mathrm{m}$ berada pada lapisan ke-10 dan lapisan yang memiliki nilai resistivitas $0,5 \Omega \mathrm{m}$ berada pada lapisan ke-13 maka dapat diketahui bahwa pada lapisan ke-10 merupakan lapisan yang mengalami intrusi air laut sehingga otomatis lapisan di bawahnya juga mengalami intrusi.

Untuk lintasan 2 dengan nilai resistivitas mulai dari 3,85-1999 $\Omega$ m, lapisan penutupnya diperlihatkan dengan citra warna hijau dengan nilai resistivitas $3,89 \Omega \mathrm{m}$ dan sama halnya dengan lintasan 1 , lapisan dengan citra penampang warna hijau diindikasikan sebagai lapisan lempung. Lalu, untuk citra warna kuning-orange dengan rentang nilai resistivitas 17,1-89,9 $\Omega$ m diindikasikan sebagai lanau dan lanau pasiran. Kemudian, untuk citra warna merah muda-merah dengan nilai resistivitas 123,3-627,9 $\Omega$ m diindikasikan sebagai lapisan pasir kerikilan hingga pasir kerakalan. Sehingga berdasarkan hal tersebut, maka pada lintasan 2 masalah intrusi air laut tidak terjadi. Sebab, nilai resistivitas intrusi 
air laut berada antara nilai resistivitas air tanah dan air laut yaitu diantara $0,2 \Omega \mathrm{m}-0,5 \Omega \mathrm{m}$. Kemudian berdasarkan fungsi akuifer sebagai lapisan yang dapat meloloskan air dan menyimpan air, lapisan air tanah yang baik untuk dikonsumsi berada pada akuifer dengan lapisan material pasir, pasir kerikilan, hingga pasir kerakalan. Sebab, air tanah yang berada pada material lempung hingga lanau memiliki kualitas yang kurang baik akibat material lempung apabila telah jenuh, maka tidak akan dapat lagi menyerap air dan material lanau merupakan jenis material yang masih mendekati dengan material lempung.

Kemudian untuk lintasan terakhir yaitu lintasan 3 dengan nilai resistivitas mulai dari 0,01-3,27 $\Omega \mathrm{m}$ (lihat lampiran 2 ), dari citra warna penampangnya yaitu warna hitambiru dengan nilai resisitivitasnya yang sangat rendah yaitu mulai dari $0,01-3,27 \Omega$ m sudah memperlihatkan dengan jelas bahwa pada lintasan ini, intrusi air laut sudah menyusup jauh hingga kesemua lapisannya. Sebab, seperti halnya penjelasan pada lintasan 1 yaitu berdasarkan penjelasan pada kajian teori mengenai intrusi air laut menyatakan bahwa dalam keadaan statis, air tawar akan mengapung di atas air asin di daerah pantai karena air asin mempunyai densitas yang lebih tinggi dari air tawar maka pada lintasan 3 , semua lapisannya telah mengalami intrusi. Adapaun pada lintasan 3 dengan nilai resistivitas lebih dari $0,5 \Omega \mathrm{m}$ juga diindikasikan sebagai intrusi air laut disebabkan karena pada lapisan kedua yaitu lapisan setelah lapisan top soil (lapisan penutup) memiliki nilai resistivitas $0,48 \Omega \mathrm{m}$ dan nilai tersebut belum mencapai nilai resistivitas untuk air tanah. Sebab, nilai resistivitas untuk air tanah adalah $0,5 \Omega \mathrm{m}$. Sehingga, karena hal tersebut maka otomatis lapisan yang berada di bawah lapisan kedua juga telah terserap oleh air asin dan lapisan tersebut diindikasikan sebagai lapisan lempung yang terserap oleh air asin. Berdasarkan hal tersebut, maka pada lintasan 3 intrusi air laut sudah menyusup jauh kedalam akuifer air tawar dan kondisi air bawah permukaan pada lintasan 3 ini sudah berupa air payau.

\section{KESIMPULAN}

Berdasarkan penelitian dan hasil interpretasi yang dilakukan diperoleh kesimpulan yaitu daerah yang telah mengalami intrusi air laut terjadi pada lintasan 1 yaitu mulai dari kedalaman 13,58-25 meter dan lintasan 3 yang semua lapisannya telah diresapi oleh air laut. Sedangkan pada lintasan 2 tidak ditemukan adanya intrusi air laut ke dalam akuifer air tanah sampai pada kedalaman 25 meter. 


\section{REFERENSI}

Ambarsari, E. S. 2013. Aplikasi Metode Geolistrik untuk Identifikasi Intrusi Air Laut Studi Kasus Semarang Utara. Skripsi. Semarang: Universitas Negeri Semarang.

Astutik, P., Wahyono,S.C., Siregar, S.S. 2016. Identifikasi Intrusi Air Laut Menggunakan Metode Geolistrik di Desa Kampung Baru, Tanah Bumbu. Jurnal Fisika Flux Vol 13 (2); 155-160.

Sutandi, M.C. 2012. Penelitian Air Tanah. Jurusan Teknik Sipil Universitas Kristen Maranatha. Bandung

Indarto. 2012. Hidrologi Dasar Teori Dan Contoh Aplikasi Model Hidrologi. Jakarta: PT Bumi Aksara.

Kodatie, R.J., 2012. Tata Ruang Air Tanah.Yogyakarta: Andi.

Salam, R., 2011. Kajian Akifer Pantai Pulau Ternate. J. Aplikasi Fisika, 7(2), 51-55.

Wijaya, L. 2009. Identifikasi Pencemaran Air Tanah dengan Menggunakan Metode Geolistrik di Wilayah Ngringo Jaten Karanganyar. In Skripsi. Universitas Sebelas Maret. 